https://doi.org/10.26512/gs.v11i3.32297

Revista Eletrônica Gestão \& Saúde ISSN: 1982-4785

Neto JMR

\title{
As fragilidades do federalismo cooperativo na crise do Covid-19
}

Artigo Teórico - Empírico

The fragilities of cooperative federalism during the Covid-19 crisis

La fragilidad del federalismo cooperativo en la crisis de Covid-19

João Mendes da Rocha Neto ${ }^{1}$

\section{Resumo}

O objetivo deste ensaio é discutir, a partir das narrativas de governantes, impactos sobre a coordenação da política de saúde no período em que o país enfrenta a pandemia do Covid19, tendo como pano de fundo as relações federativas. $\mathrm{O}$ argumento teórico foi balizado pelo debate em torno do federalismo e da coordenação, enfatizando a política de saúde na aproximação com os fatos analisados. Os elementos dessa fragilidade estão expressos nas falas de governantes e outros atores importantes, tanto em veículos da imprensa, como em documentos oficiais, destacando como tais episódios constituem-se em uma fragilidade, mesmo que momentânea, das relações entre o governo central e os estados. Adicionem-se a esse fato as medidas institucionais que evidenciaram essa persistente tensão entre o governo central e governantes subnacionais no enfrentamento da crise do Covid-19. Entende-se que o ensaio capturou apenas uma sequência de fatos, que devem ter novos elementos de tensão até que o país supere a fase mais aguda da crise do Corona vírus.

Palavras-chave: Gestão da Saúde da População; Políticas de Saúde; Capacidade de Liderança e Governança; Sistemas Públicos de Saúde; Covid-19.

\begin{abstract}
The objective of this essay is to discuss, based on the narratives of governors, the impacts on the coordination of health policy at a time when the country is facing the Covid-19 pandemic, in the context of federative relations. The theoretical argument was guided by the debate on federalism and coordination, emphasizing health policy when addressing the facts analyzed. The elements of this fragility are expressed in the statements of governors and other important actors, both in the media and in official documents, highlighting how such episodes constitute a fragility, albeit momentary, in relations between the central government and the states. In addition to that, the institutional measures that showed this persistent tension between the central
\end{abstract}

\footnotetext{
${ }^{1}$ Mestre e Doutor em Administração Pública. Docente do Programa de Pós-graduação en Administração da Universidade de Brasilia. Brasília, Distrito Federal - Brasil. - Orcid: https://orcid.org/0000-0002-2306-992X
} 
Revista Eletrônica Gestão \& Saúde ISSN: 1982-4785 Neto JMR

government and the sub-national governments, facing the Covid-19 crisis. It is understood that the trial captured only one sequence of events, which must have new elements of tension, until the country passes the most acute phase of the Corona virus crisis.

Key words: Population health management; Health policies; Leadership and Government Capacity; Public health systems; COVID-19.

\section{Resumen}

El objetivo de este ensayo es discutir, con base en las narrativas de los gobernantes, los impactos en la coordinación de la política de salud en un momento en que el país se enfrenta a la pandemia de Covid-19, en el contexto de las relaciones federativas. El argumento teórico fue guiado por el debate sobre el federalismo y la coordinación, haciendo hincapié en la política de salud al abordar los hechos analizados. Los elementos de esta fragilidad se expresan en las declaraciones de los gobernantes y otros actores importantes, tanto en los medios como en documentos oficiales, destacando cómo tales episodios constituyen una fragilidad, aunque sea momentánea, en las relaciones entre el gobierno central y los estados. Además de eso, las medidas institucionales que mostraron la tensión persistente entre el gobierno central y los gobiernos subnacionales, frente a la crisis de Covid-19. Se entiende que el ensayo capturó solo una secuencia de hechos, que
As fragilidades do federalismo cooperativo... deben tener nuevos elementos de tensión, hasta que el país supere la fase más aguda de la crisis del virus Corona.

Palabras clave: Gestión de la salud de la población; Politicas de salud; Liderazgo y Capacidad de Gobierno; Sistemas de salud pública; COVID-19.

\section{Considerações Iniciais}

A gestão do Presidente da República tem sido marcada pela postura conflituosa em relação a grupos sociais e determinados temas, enfraquecendo-os na agenda de políticas públicas. Isso leva a um ambiente de tensionamento com evidentes repercussões na gestão pública, atingindo órgãos de governo e políticas públicas e afetando tanto a participação da sociedade civil como a relação com os demais entes federados.

No entanto, no contexto da crise do Covid-19, essas disputas se acirraram, denotando um problema de ausência de coordenação por parte do governo federal que, em alguns momentos, adotou medidas controversas no enfrentamento do problema e deslocou o centro dos conflitos para os governos subnacionais, por narrativas e comportamentos que sinalizaram uma tendência ao conflito de posições, levando à instabilidade das relações federativas.

É importante demarcar que, de março a junho de 2020, o país foi tomado por uma divisão com distintas gradações que antagoniza a saúde de um lado e a economia do 
Revista Eletrônica Gestão \& Saúde ISSN: 1982-4785 Neto JMR

outro, intensificada pelo discurso presidencial frente às medidas adotadas pelos governos estaduais, principalmente aquelas relacionadas ao isolamento social. Isso teve claras repercussões no enfrentamento à pandemia, impondo uma reflexão sobre o Sistema Único de Saúde: até onde a organização sistêmica do Estado brasileiro, no setor saúde, consegue se sobrepor a falhas de coordenação e comportamentos políticos conflituosos como aqueles observados durante a pandemia do COVID-19?

Portanto, o objetivo do ensaio é discutir, a partir das narrativas de governantes, impactos sobre a coordenação da política de saúde no período em que o país enfrenta a pandemia do Covid-19, tendo como pano de fundo as relações federativas. A análise dessa narrativa foi subsidiada por matérias em alguns veículos de impressa tais como Folha de São Paulo, o Estado de São Paulo, o Globo e Correio Braziliense, nos meses de fevereiro a junho de 2020.

O ensaio partiu de uma revisão de literatura, que lançou mão de obras de campos de conhecimento distintos, enfatizando a dimensão da coordenação e das relações federativas e verticalizando o debate na política de saúde. Os recursos discursivos foram incorporados com base no método narrativo adotado por Barzelay e Cortázar ( 1 ) para análise de políticas públicas, aplicando-o aos fatos, produzindo os elementos necessários
As fragilidades do federalismo cooperativo... para a reflexão. Adicionalmente, foram consultados os documentos oficiais Plano de Enfrentamento ao COVID-19 do Ministério da Saúde e Portarias que disciplinaram as ações do mesmo órgão, além de manifestações institucionais que permitiram apreciar as fragilidades das relações federativas, objeto do presente ensaio, sob um olhar interpretativo acerca das tensões entre entes federados e poderes da República.

\section{Coordenação e federalismo: breve contextualização teórica}

O conflito entre os entes federados não data de hoje no Brasil. Autores como Ribeiro, Moreira, Ouverney, Pinto, Silva ${ }^{(2)}$, Carvalho e Afonso( ${ }^{3}$ ) e $\operatorname{Souza}^{(4)}$ relatam essa trajetória de disputas, mas enfatizam que sempre estiveram mais concentradas na questão dos recursos para financiamento de políticas públicas.

Um dos setores que mais acumulam conflitos interfederativos, alguns deles chegando à judicialização, é a saúde, apesar de a concepção do Sistema Único de Saúde (SUS) promover um equilíbrio na participação dos governos subnacionais. Parte das tensões apontadas por estudiosos nas relações federativas derivam das falhas de coordenação das políticas públicas nacionais, que asseguram amplo protagonismo e poder de decisão estratégica na mão do governo central, cabendo aos estados e municípios uma atuação Rev. Gestão e Saúde (Brasília ). v. 11 n. 3 (2020): Setembro - Dezembro 2020 
Revista Eletrônica Gestão \& Saúde ISSN: 1982-4785 Neto JMR

residual, contrariando o que Menicucci, Costa, Machadol. ${ }^{(} 5$ ) caracterizam como “dispersão de poderes", conforme se observa nos princípios da $\mathrm{CF} / 88$, que demarca os espaços de atuação dos entes federados. Se, por um lado, esse formato fortalece o arranjo da política pela presença da União como protagonista, por outro lado, pode também ser um fator de suscetibilidade, em face da excessiva centralidade nas decisões estratégicas, já apontadas por Carvalho e Afonso $^{(3)}$, quando algum problema de coordenação se expressa, a exemplo do que ocorreu durante a Pandemia do Covid-19.

A coordenação das ações e as relações federativas no contexto da pandemia da Covid 19 adquire centralidade em face dos episódios da vida política brasileira, noticiadas pela imprensa, que possibilitou verificar narrativas conflitantes entre os Poderes da União e entre os governantes nos três níveis da federação. Portanto, é importante compreender que a efetividade das medidas está associada à capacidade de coordená-las diante da magnitude e complexidade da pandemia, segundo Schmidt, Mello, Cavalcante ( 6 ).

Aqui se abre um parênteses para entender os elementos fundamentais do que seria a coordenação, destacados por Lotta, Gonçalves, Bietelman ( 7 ) , definindo-a como um processo de criação e aplicação de regras com a finalidade de orientar decisões de diferentes atores em torno de um mesmo
As fragilidades do federalismo cooperativo... campo e destacam ainda que, no caso das políticas sociais do Brasil, entre elas as de saúde, a formulação via normas e o financiamento estão centralizados na União, cabendo aos entes subnacionais a atribuição de implantá-las.

Quando se trata de saúde, os pressupostos da coordenação em políticas públicas adquirem centralidade, constituindose em elemento fundamental ao enfrentamento da pandemia, considerando a extensão e complexidade do país quando se trata da capacidade de cooperação dos entes federados na superação do problema.

$\operatorname{Souza}^{(} 8$ ) amplia o debate sobre a coordenação, alcançando aspectos políticos e destacando que a legitimidade e o poder para coordenar associa-se à liderança dos mandatários e não dos administradores, ou seja, há que se considerar a capacidade dos políticos na orientação dos quadros técnicos e na promoção do diálogo federativo, o que pode vir a ter repercussões se a componente do conflito ideológico partidário entrar em cena.

De forma complementar, Gaetani ${ }^{(} 9$ ) encaminha sua reflexão sobre coordenação centrando-se na capacidade dos chefes de governo a partir de preferências pessoais e de suas visões frente a conjunturas políticas e econômicas, alertando que a ausência dessa habilidade pode levar ao aumento dos conflitos horizontais e verticais. Portanto, os requisitos necessários para coordenação em políticas 
Revista Eletrônica Gestão \& Saúde ISSN: 1982-4785 Neto JMR

públicas não estão dados unicamente pelo arcabouço legal nem tampouco pela institucionalidade de quem articula; existem aspectos personalistas que interferem diretamente nessa liderança.

A institucionalidade na coordenação das políticas nacionais varia bastante e, como destacam Menicucci, Costa, Machado ( 5 ) , a cooperação federativa para a consecução de objetivos depende não só da natureza dos problemas a se enfrentar, mas também dos incentivos institucionais existentes. De forma geral, a política de saúde é uma das mais citadas quando se deseja exemplificar um arranjo federativo bem sucedido, seja em função da forte participação social seja em decorrência da territorialização, abarcando a complexidade do país e do seu arranjo federativo, como preconizado por Souza e $\operatorname{Costa}^{\left(1^{0}\right)}$. Tudo isso alicerçado em uma tripartição de poderes e atribuições formalizada por meio de um conjunto de normas e outros instrumentos infralegais.

A forma reticular do arranjo de governança constitui-se um enorme desafio para todos os atores envolvidos, mas com um grau de responsabilidade maior no governo federal, considerando que dele se espera, por força das atribuições constitucionais e do poder de financiamento, além da capacidade técnica, as macro orientações da política de saúde. Essa verticalização é corroborada por Carvalho e Afonso ( 3 ) em sua crítica, ao dizer
As fragilidades do federalismo cooperativo... que a política de saúde foi criada em um modelo top-down e que a cooperação é uma imposição.

Na saúde, as expectativas são atendidas de forma diferenciada, permitindo a continuidade do funcionamento do SUS apesar dos conflitos estruturais e conjunturais sintetizados por Ribeiro e $\left.\operatorname{Moreira}^{(}{ }^{11}\right)$, ao apontarem que, na política de saúde, o federalismo cooperativo se configura um pacto de não responsabilização dos entes federados, onde a inércia toma o lugar da contratualização e da reponsabilidade.

Apesar de uma potente armadura institucional existir no setor saúde, há uma trajetória de tensões de toda natureza, presidida pelas disputas em torno do financiamento e pelas distintas capacidades dos entes subnacionais frente às exigências da ampliação no atendimento, bem como da necessidade em performar melhor e alcançar resultados no caminho de um modelo gerencial, destacado por Carnut e Navai ${ }^{(12)}$. Nesse aspecto, reside o fundamento das falhas de cooperação, como destacado por Ribeiro, Moreira, Ouverney, Pinto, Silva ${ }^{(2)}$, repercutindo na distribuição dos serviços e, consequentemente, no seu acesso por parte da população, especialmente quando se trata da provisão em atenção primária, revelando a insuficiência dos serviços e a inequidade regional no acesso a eles. Fato que a descentralização não foi capaz de reparar, segundo os autores mencionados. 
Revista Eletrônica Gestão \& Saúde ISSN: 1982-4785 Neto JMR

Esse quadro se revela nas unidades de saúde, das mais elementares até os hospitais de referência, corroborando a presença cotidiana do tema na vida dos brasileiros que assistem o sistema se estressar, na maior parte das vezes, pela insuficiência para o financiamento pleno, repercutindo na falta de insumos elementares para o seu funcionamento. Miranda, Mendes e Silva $\left(1^{9}\right)$ alertam para o problema ao dizer que a insuficiência de recursos financeiros constitui-se um dos maiores desafios do SUS quando se trata da equidade e integralidade no atendimento.

Em artigo que estudou os gastos dos municípios brasileiros, Araújo, Gonçalves e Machado ( $1^{4}$ ) apontam aspectos relevantes para se compreender tais assimetrias e os problemas do subfinanciamento: a) as receitas municipais, quando aplicadas à saúde, estão fortemente concentradas em pessoal, considerando que a Lei n. 8080/1991, em seu artigo 18 , reserva ao poder local a função de gerir os serviços públicos de saúde em um setor que demanda intensivamente mão de obra especializada; b) para os menores municípios, além das questões anteriores, existe a dificuldade de cobrir procedimentos de média e alta complexidade em face dos custos e da escala; c) a proporção de idosos no universo da população pressiona, sobremaneira, os gastos locais, devido ao acúmulo de problemas crônicos e à complexidade dos tratamentos; d) a maior capacidade de elevação dos gastos
As fragilidades do federalismo cooperativo... municipais na saúde implica melhoria das condições de vida das populações; e) nos municípios de pequeno porte, há uma tendência a formalizar contratos com Organizações Sociais como forma de superar as dificuldades em acessar os serviços de média e alta complexidade; f) a insuficiência dos valores transferidos da União para cobrir procedimentos de média e alta complexidade impõe aos municípios gastos crescentes de complementação.

Se, de um lado, a crise da saúde tornase uma constante, de outro, o arranjo do sistema continua a operar para o enfrentamento das questões estruturais, alternando a priorização do tema na agenda de governo, embora seja um consenso que, aliada à educação, a saúde deve presidir investimentos, e, com isso, perseguir resultados que modifiquem o quadro de inequidade já apontado.

\section{Elementos conjunturais de um federalismo}

\section{(não) cooperativo sob a égide da crise do}

\section{Covid-19}

Desde o início do seu governo, o Presidente da República vem estabelecendo uma relação tensa com os mandatários dos estados e autoridades dos outros poderes, notadamente aqueles que lhe fazem oposição e, desde a chegada da Covid-19 ao Brasil tais episódios se intensificaram, conforme Rossi e Silva $^{\left(1^{5}\right)}$. Trata-se de uma disputa de 
Revista Eletrônica Gestão \& Saúde ISSN: 1982-4785 Neto JMR

posições políticas e agendas de governo, de forte cunho ideológico, simplificada na oposição: saúde versus economia. E o pano de fundo dessa contenda centrou-se em uma narrativa de tensionamento crescente, aproximando-se de um ambiente de campanha eleitoral, secundarizando a importância de uma trégua nas disputas políticas, bem como, de uma ação coordenada do governo federal, denotando falhas de coordenação para superar a crise gerada pela pandemia do Covid-19.

Do ponto de vista da coordenação do governo federal, a primeira ação ocorreu no início de fevereiro de 2020 com a repatriação dos brasileiros que habitavam a cidade de Whuan, na China, cidade onde se originou a pandemia. Na ocasião, uma operação que envolveu a Força Aérea Brasileira (FAB) trouxe ao Brasil 34 pessoas, que ficaram em isolamento durante 14 dias na base militar de Anápolis-GO. Naquele momento, o Congresso Nacional aprovou em regime de urgência uma legislação específica no sentido de amparar o isolamento que seria imposto, tendo o Presidente do Senado, Davi Alcolumbre, afirmado que "[...] se o presidente tomar essa decisão, terá o nosso total e irrestrito apoio. [...] A Câmara e o Senado vão trabalhar para agilizar e votar essa lei em regime de urgência" ( $1^{6}$ ), sinalizando disposição do legislativo para colaborar, de forma célere, com o poder executivo nas primeiras iniciativas frente a pandemia.
As fragilidades do federalismo cooperativo...

Em meados de fevereiro, o Ministério da Saúde lançou o Plano de Contingência Nacional para Infecção Humana pelo novo Coronavírus Covid-19( $\left.1^{7}\right)$, tendo o primeiro caso se manifestado no dia 26 daquele mês, importado da Itália, que já se encontrava em processo intenso de contaminação. Dois dias depois, em 28 de fevereiro, o Ministério da Saúde lançou a primeira grande campanha publicitária sobre a Covid-19, centrada nas informações sobre os cuidados de assepsia a serem adotados. $\mathrm{Na}$ ocasião, as medidas propostas pelo Plano se dividiam nos níveis de resposta alerta, perigo eminente e emergência de saúde pública de importância nacional, não havendo entre as ações nada que remetesse ao distanciamento social como recurso para o controle da infecção.

Adicionalmente, na leitura do documento, se observam menções aos governos subnacionais sempre no papel de fornecedores de informações para o Ministério da Saúde, retirando de municípios e estados qualquer espaço nos processos decisórios, o que caracterizou excessiva centralização no governo federal, conforme já fora apontado por Carvalho e Afonso ( 3 ) em suas reflexões sobre essa característica disfuncional na coordenação de políticas públicas.

Embora os casos continuassem aumentando no Brasil, as iniciativas federais e dos governos estaduais ainda não incorporavam a recomendação da Organização 
Revista Eletrônica Gestão \& Saúde ISSN: 1982-4785 Neto JMR

Mundial de Saúde (OMS) de isolamento radical - lockdown, já adotada por alguns países, como a Itália. Foi somente em meados de março, quando o Governo do Distrito Federal tomou medidas restritivas publicando decreto que suspendia as aulas e eventos, que medidas similares foram adotadas em outras unidades da federação. Koga, Palotti, Goellner e Couto $\left(1^{8}\right)$ destacam a tempestividade dos estados nas medidas restritivas. Estava posto o principal ponto de discórdia entre os governadores e o Presidente da República, que, em meio a cobranças por respostas do governo federal em relação aos efeitos econômicos do isolamento social, advogava pela adoção do isolamento vertical, o qual incluiria somente os grupos de risco, idosos e pessoas portadoras de comorbidades.

A postura do Presidente foi percebida por alguns governadores, a exemplo de Ronaldo Caiado, do estado de Goiás, como um desrespeito às medidas adotadas, tensionado a relação a ponto de causar uma altercação pública entre o Presidente da República e o governador que assim expressou tal episódio: “[...] essa situação conflituosa dá ganhos políticos ao presidente (...) ele vai estar em condição de dizer que a economia explodiu e o desemprego aumentou"( 19 ). Caiado destacou, ainda, que o Presidente se utilizaria do argumento de ter alertado para uma intensificação do desemprego em face das
As fragilidades do federalismo cooperativo... medidas adotadas, não sendo escutado pelos mandatários estaduais.

Dessa forma, o Presidente da República, que possuía forte base de apoio entre os governadores, excetuando-se aqueles da Região Nordeste, se vê contestado por aliados de outrora, a exemplo do Governador Wilson Witzel (RJ) e do Governador João Dória (SP), em clara postura de disputas de narrativas, o que sugere uma antecipação do processo eleitoral de 2022. Ou seja, a política partidária contamina a coordenação da política pública de saúde e as medidas econômicas para o enfrentamento da pandemia, relembrando aquilo que $\operatorname{Souza}^{(} 8$ ) e $\operatorname{Gaetani}^{(} 9$ ) já destacaram como aspecto que se reflete na coordenação de políticas públicas.

Essa tensão entre os governadores e o Presidente da República também decorre da postura reativa do Ministério da Saúde na adoção de ações com vistas a dotar o SUS dos recursos necessários para o enfrentamento da pandemia, a exemplo das aquisições de respiradores, medicamentos ou mesmo de Equipamentos de Proteção Individual (EPI's) para os profissionais da linha de frente. A ausência de estratégias de colaboração nas aquisições e contratações constituiu-se um elemento de acirramento das disputas, expresso nas narrativas, e acabou por onerar os cofres dos estados e até mesmo da União, considerando que somente em junho o Ministério da Saúde disciplinou o fluxo para o 
Revista Eletrônica Gestão \& Saúde ISSN: 1982-4785 Neto JMR

atendimento de necessidades dos governos subnacionais, por intermédio da Portaria $n^{\circ}$ 1.587 , de 19 de junho de $2020^{(} 2^{0}$ ) . Vale aqui relembrar que Ribeiro e $\operatorname{Moreira}^{(11)}$ destacam a inércia como um aspecto que marca o SUS, situação agravada quando existe falha de coordenação.

Os movimentos de aproximação entre o governo federal e os estados sofreram altos e baixos durante a trajetória de expansão dos casos da Covid-19 no país. Reuniões foram realizadas entre governadores e o Presidente, muitas delas marcadas pelo tensionamento em face das declarações do mandatário, colocando por terra as deliberações do coletivo e instaurando um ambiente de desconfiança na governança para o enfrentamento da pandemia.

Outro ponto de enfrentamento entre a União e os governos subnacionais associa-se ao decreto de calamidade aprovado pela Câmara. A medida ampliou o leque de ações do poder público em meio ao combate à pandemia, amparando legalmente os governos federal, estaduais e municipais na adoção de medidas excepcionais nas compras e contratações, além de prever o confisco de materiais sanitários em empresas. Essas ações, no entanto, resultaram em conflitos, como aquele ocorrido no Amapá, onde o governo federal confiscou 25 aparelhos respiradores adquiridos pelo governo estadual, que, para
As fragilidades do federalismo cooperativo... assegurar a permanência dos equipamentos no estado, recorreu à Justiça Federal.

A pouca resolutividade e o fraco diálogo entre os governantes tornou o poder judiciário uma peça central na mediação de contendas. Essa judicialização implicou a instabilidade da governança para o enfrentamento da pandemia, decorrente da baixa capacidade de coordenação do governo central e da ausência de normas claras. Em meio ao ambiente conflituoso, a Ordem dos Advogados do Brasil (OAB) impetrou ação, julgada procedente, assegurando a Estados e Municípios a autonomia para adotar medidas de isolamento, contrariando o Presidente, que assim se manifestou: "Quem reabre o Brasil não sou eu, é governador e prefeito. Eu não tenho poder nenhum (...) O Supremo decidiu: quem fecha ou abre é governador e prefeito"( $\left.^{21}\right)$, em 14 de abril, ao conceder entrevista.

Nos momentos de maior tensionamento, aos governadores e ao Ministro da Saúde foram endereçadas ameaças, quando o Presidente anunciou que publicaria instrumento legal relaxando parte das medidas estaduais, o que igualmente não logrou êxito, em face de mais uma decisão da suprema corte. O Fato sinaliza para uma postura de imposição de regramentos, contrariando o princípio da estabilidade que caracteriza a governança em rede, conforme apontado por Bevir( ${ }^{22}$ ). 
Revista Eletrônica Gestão \& Saúde ISSN: 1982-4785 Neto JMR

Ainda nessa perspectiva, há uma postura ambígua do Presidente em relação aos princípios constitucionais quanto à autonomia reservada aos governos subnacionais, alternando declarações como as já mencionadas com aquelas feitas em entrevista em abril, quando declarou: "Respeito a autonomia dos governadores e prefeitos. Muitas medidas, de forma restritiva ou não, são de responsabilidade exclusiva dos mesmos. $\mathrm{O}$ governo federal não foi consultado sobre sua amplitude ou duração" ( 23 ) , em um aparente desconhecimento das competências dos governos subnacionais em relação ao enfrentamento da pandemia, conforme já fora decidido pelo poder judiciário.

A trajetória de tensionamento também acentuou o desgaste e levou à demissão do Ministro da Saúde, Henrique Mandetta, que abalizou as medidas adotadas pelos governos estaduais e municipais, contrariando $\mathrm{o}$ Presidente da República. Tratando-se de um episódio emblemático da forma como o mandatário encara as posições que se opõem às suas convicções em relação ao enfrentamento da pandemia, o que remete ao debate feito por $\operatorname{Souza}^{(} 8$ ) e $\operatorname{Gaetani}^{(}{ }^{9}$ ), quando analisaram o efeito das preferências pessoais do líder na coordenação de políticas públicas. Essa situação reforça o conflito federativo que se estabelecera em torno da dicotomia saúde versus economia na visão do Presidente, que, desde o início da crise, adotou um discurso de
As fragilidades do federalismo cooperativo... que o país iria quebrar economicamente em face das medidas adotadas pelos governadores.

Ou seja, observa-se a ausência de uma postura cooperativa, que contribua para a confiança da população nas medidas de enfrentamento ao Covid-19, bem como nas estratégias de superação da crise econômica que se deve seguir. Isso levou a um quadro de perdas de capital político para todos os envolvidos, pois, nas primeiras pesquisas que mediam a confiança da população em relação ao Presidente e aos Governadores no enfrentamento da pandemia, havia considerável aprovação desses últimos, quadro que foi se modificando, igualando os governantes dos estados ao Presidente, que, na série da pesquisa, nunca apresentou bom desempenho.

O processo de 'retirada' do Ministro Mandetta se deu em um crescente de movimentos, que incluíram o Presidente da República descumprindo as recomendações dos especialistas e saindo às ruas sem proteção, além de uma estratégia de enfraquecimento da centralidade do ministério, chegando a deslocar a relação com a imprensa para dentro do Palácio do Planalto. Transmitiu, assim, uma mensagem de que a coordenação agora estaria no entorno do Presidente, o que poderia, em um primeiro momento, ser interpretado como a elevação do tema a patamar prioritário, mas que logo se desfez quando se verificou a pouca 
Revista Eletrônica Gestão \& Saúde ISSN: 1982-4785 Neto JMR

frequência do mandatário e do Centro de Governo nas coletivas de imprensa.

Como a troca de Ministro se deu em plena escalada da contaminação, um fato chamou atenção: os presidentes do Conselho Nacional de Secretários Estaduais de Saúde e do Conselho dos Secretários Municipais de Saúde não foram convidados a participar da posse de Nelson Teich ${ }^{2}{ }^{4}$, conforme divulgado pela imprensa, tornando-se mais um elemento de tensão na relação com os entes federados. Tal fato corrobora o afastamento do governo federal da instância colegiada dos gestores de saúde estaduais, um dos fatores que compromete a coordenação e governança em uma política pública, sobretudo no momento que as ações governamentais necessitam de concertação.

Ao completar um mês à frente da pasta, o Ministro Teich pediu exoneração do cargo, que passou a ser ocupado pelo General Pazuello, com perfil voltado para a área de logística, que nomeou outros tantos militares para postos-chave no Ministério da Saúde. Já nos primeiros dias, o ministro adotou medidas controversas, com a modificação do método de contagem de infectados e óbitos, além da interrupção das coletivas de imprensa diárias, tão necessárias para posicionar governantes, especialistas e a população de forma geral sobre o avanço da pandemia no país. Mais uma ação que mereceu reparação do judiciário, pois o Supremo Tribunal Federal (STF) determinou
As fragilidades do federalismo cooperativo... o retorno das informações no Portal, assim como o Tribunal de Contas da União (TCU) elaborou Relatório contendo recomendações que enfatizavam a transparência e governança no enfrentamento ao Covid-19.

No caso das prefeituras, a reação às falas do Presidente foi formalizada pela Frente Nacional dos Prefeitos, que teceu duras críticas à sua capacidade de coordenação e aos impactos dessa falha para a federação ao dar publicidade, na forma de Nota, que alertava "Não contar com essa liderança, e, pior, contar com uma postura irresponsável, alicerçada em convicções sem embasamento científico, que semeiam a discórdia e até mesmo a convulsão social, compromete as relações federativas" ( ${ }_{2} 5$ ).

É compreensível a atitude de governadores e prefeitos, pois, embora o Sistema Único de Saúde seja um arranjo tripartite, é nas unidades estaduais e municipais que os problemas se manifestam. Diante do sistema pressionado, tendo o exministro da Saúde já alertado que haveria um colapso, as posturas reativas e condenatórias às palavras e atitudes do Presidente por parte dos governantes estaduais e locais são um prenuncio do ônus político que recairá sobre todos eles com a intensificação da curva de contaminação e do aumento dos óbitos. O alerta feito por pesquisadores do IPEA aponta para a importância dessa relação federativa e destaca que as condições político 
Revista Eletrônica Gestão \& Saúde ISSN: 1982-4785 Neto JMR

institucionais, entre elas a coordenação, são um recurso essencial para apoiar os estados e que elas estão reunidas no governo central, conforme apontado por Lopez, Palotti, Tolentino e $\left.\operatorname{Koga}^{(} 2^{6}\right)$.

Outros episódios colaboram para o ambiente de instabilidade na governança do enfrentamento ao Covid-19, tais como no caso da importação feita pelo governo do estado do Maranhão, em que a Receita Federal manifestou-se pela abertura de apuração no sentido de responsabilizar o governador, que havia montado uma operação logística para trazer diretamente da China alguns equipamentos. Mais recentemente, as operações da Polícia Federal autorizadas pelo poder judiciário, decorrentes de investigações sobre malversação de recursos públicos em compras e contratações dos governos estaduais, foram objeto de pronunciamento do Presidente da República, reforçando suas críticas a adversários, procurando associá-los a esquemas de corrupção, secundarizando o fato de que parte do problema se deveu às falhas de coordenação do governo central, considerando seu poder de negociar em face da escala e dos instrumentos legais disponíveis.

Outro fato que envolveu os governos subnacionais e contribuiu para o tensionamento nessa trajetória conflituosa entre o Presidente, Governadores e Prefeitos foi a votação das medidas de socorro aos governos estaduais e municipais, o
As fragilidades do federalismo cooperativo... denominado Plano Mansueto, bastante reformulado pelo Congresso Nacional. Para o Presidente da República, “[...] pegaram o plano Mansueto e resolveram simplesmente, a parte que interessava para eles, aprovar. A parte que não interessava, não aprovava". Já o Presidente da Câmara, compreendeu que "Da parte dos governadores, me parece que esse encaminhamento vai bem, atende a todos. O que gostaríamos é que a gente possa construir isso junto com a equipe econômica para que a gente tenha uma harmonia maior" ( $2^{7}$ ).

Isso foi visto pelo Presidente da República como um movimento político com três frentes: a) demarcar o relevante papel do legislativo no enfrentamento da pandemia; b) enfraquecer o ímpeto reformista, coordenado pelo Ministério da Economia, sinalizando limites as estratégias do executivo; e c) angariar simpatia, e apoio político, dos governantes municipais e estaduais, que passam a vislumbrar no Presidente da Câmara um aliado de primeira hora na superação da aguda crise fiscal dos entes federados, intensificada pela Covid-19. Assim, o Plano Mansueto, enviado pelo governo federal ao Congresso, em meados do ano de 2019, que instituiria o Plano de Equilíbrio Fiscal (PEF), sofreu mudanças substantivas na sua proposta original, que elencava algumas exigências para municípios e estados acessarem crédito com garantia do Tesouro Nacional. 
Revista Eletrônica Gestão \& Saúde ISSN: 1982-4785 Neto JMR

Em lugar do PEF, surge o Programa Emergencial de Apoio a Estados e Municípios no Combate ao Coronavírus, que suspende temporariamente o pagamento de dívidas, prevê que a União compense a queda de arrecadação e permite que os entes subnacionais contratem operações de crédito com garantia da União em um valor correspondente a até $8 \%$ da Receita Corrente Líquida, desde que o dinheiro seja aplicado na prevenção e combate ao Covid-19 ou para a estabilização da receita. Os estados e municípios não precisarão apresentar contrapartidas e as medidas saneadoras previstas no texto original do Plano Mansueto foram retiradas do substitutivo.

Nesse contexto, o governo federal interpretou a aprovação do Programa como um obstáculo à sua agenda de reformas macroeconômicas e apontou o Presidente da Câmara como o líder e articulador para que isso ocorresse. Esse fato elevou a tensão entre os poderes e as concessões feitas aos governos subnacionais, levando o governo federal a intensificar sua narrativa de conflito em relação aos governantes estaduais. Ressalte-se que o impacto aos cofres do Tesouro Nacional já vinha ocorrendo em face da suspensão do pagamento de parcelas das dívidas dos governos estaduais via decisões judiciais desde o início da crise do Covid-19.

É necessário dar um passo atrás para entender que esse conflito situa-se em um
As fragilidades do federalismo cooperativo... contexto institucional que envolve o atual Presidente da República e os demais poderes. Em um cenário analisado por Almeida ${ }^{\left(2^{8}\right)}$, ao dizer que essa centralidade do legislativo resulta de um arranjo político forjado pelo próprio Presidente da República e da sua frágil base de apoio, e que os atritos decorrem da inabilidade do Presidente para construir uma agenda cooperativa, ou seja, a dificuldade de tecer essa arquitetura política está na raiz do conflito entre os poderes durante a crise do Covid-19.

O tensionamento se aproximou de crise institucional, havendo necessidade de uma carta de apoio de 18 governadores aos presidentes da Câmara dos Deputados e do Senado Federal, em 18 de abril, em que conclamam que "Consideramos fundamental superar nossas eventuais diferenças através do esforço do diálogo democrático e desprovido de vaidades [...]" $\left.]^{\prime 9}\right)$. Trata-se de um desagravo às críticas feitas pelo Presidente da República ao Congresso Nacional.

Some-se ao cenário descrito o fato que a pandemia impõe uma agenda emergencial e a consequente ampliação dos gastos públicos, contrariando o que planejava a equipe econômica para o ano de 2020, i.e., as reformas administrativa e tributária, colocando o país em um cenário de incerteza, que não é exclusividade do Brasil. Assim, as reformas capitaneadas pelo Ministro da Economia foram secundarizadas, para dar lugar a uma agenda de 
Revista Eletrônica Gestão \& Saúde ISSN: 1982-4785 Neto JMR

urgências, que vão desde socorrer contingentes populacionais tradicionalmente vulneráveis até abrir linhas de financiamento para o setor empresarial, passando naturalmente por um plano de aquisição de equipamentos de saúde para o combate à pandemia, o que requereu ampliação de recursos, instituindo, inclusive, um orçamento separado, denominado 'orçamento de guerra', votado pelo Congresso Nacional, assim como outras medidas urgentes, que totalizam $\mathrm{R} \$ 1,17$ trilhão (gov.br/todosportodos, acesso em 15 de junho de 2020).

A persistência da narrativa conflituosa e a ausência de uma estratégia para saída do isolamento reclama uma ação do governo federal com base em evidências e de forma planejada, como destaca Moraes ( 90 ), ao dizer que as medidas devem se basear na opinião de especialistas e nos estudos disponíveis. Dessa forma, apesar de uma extensa agenda de medidas emergenciais, já mencionadas, os governos subnacionais e a sociedade ainda aguardam a sinalização de ações estruturantes para o pós-crise.

\section{Considerações Finais}

As reflexões expostas neste ensaio buscaram analisar como a Covid-19 acentuou uma relação já estressada entre o Presidente da República e os governadores, além de envolver o Congresso Nacional e o Poder Judiciário, a partir de narrativas em torno das medidas
As fragilidades do federalismo cooperativo... adotadas durante $\mathrm{o}$ enfrentamento da pandemia.

Os discursos presidenciais ambíguos que transitam entre a postura moderada em defesa da saúde da população e um tom mais agressivo de profetizar uma crise econômica, que já estava sinalizada para o país independentemente da pandemia, dão o tom do conflito, acirram o ambiente institucional e fragilizam as relações federativas.

Os episódios conflituosos sugerem, também, a adoção de uma estratégia em que os governos subnacionais são partícipes, em duas dimensões: a) antecipa-se a campanha eleitoral de 2022, a partir de uma narrativa que opõe qualquer governante ao Presidente, caso a linha ideológica não esteja completamente alinhada, inclusive em relação às medidas de isolamento, utilizando a potência das redes sociais e dos veículos de comunicação de massa.

Ainda deve ser levado em consideração que o Presidente já não conta com uma ampla base parlamentar nem com o apoio incondicional de boa parte dos governadores, como fora no início do seu mandato. Logo, sua estratégia de prévio enfraquecimento a possíveis adversários requer episódios conflituosos, que a crise do Covid oportunizou; e b) justifica-se a interrupção da agenda de reformas macroeconômicas que já não demostravam o folego propalado e encontravam resistências nos governadores e 
Revista Eletrônica Gestão \& Saúde ISSN: 1982-4785 Neto JMR parlamentares da oposição. Portanto, a estratégia da polarização contribui para partilhar o arrefecimento das reformas, culpabilizando a flexibilização do espaço fiscal para o enfrentamento da crise.

A frustração com os resultados da economia e as apostas feitas nos marcos reformadores durante o ano de 2019, e que estavam por vir no ano de 2020, deram lugar a uma ampliação de gastos sem precedentes, contrariando a fórmula que até então orientava o discurso presidencial pautado pelo liberalismo econômico.

Isso coloca o Presidente da República em uma posição defensiva, justificando que o fracasso de suas principais agendas macroeconômicas, perante a massa de desempregados e do seu eleitorado, cioso que o mandatário conseguiria superar a crise, mesmo com a economia mundial declinando, antes mesmo do Covid-19, decorre das medidas adotadas pelos governos subnacionais.

Esses elementos alicerçam o discurso presidencial, que mescla desconhecimento dos ritos institucionais que envolvem o mandatário de um país, corroborando uma narrativa que antagoniza o presente e o futuro, a saúde e a economia, como se fosse possível essa visão simplificada.

Além do debate político, a crise do Covid-19 deixa para a administração pública algumas lições; a) a armadura de uma política
As fragilidades do federalismo cooperativo... pública, organizada em sistema e fortemente regulada, não subsiste a uma gestão inconsequente; b) as alternativas encontradas nos momentos de crise prejudicam a ação coletiva quando não se tem uma coordenação de qualidade; c) situações de forte estresse abrem possibilidades para corrupção, mas também devem ser objeto de reflexão, analisando-se as limitações impostas pela conjuntura; d) a organização territorial do SUS revelou aquilo que já se discutia: a distribuição desequilibrada dos equipamentos de média em alta complexidade, criando um segmento de cidadãos sem saúde; e) o país e sua administração pública não estão preparados para o enfrentamento de situações de crise, e isso já ficou evidente nos episódios recentes de grandes desastres ambientais; e f) a participação social depende de uma luta continuada, pois a sociedade e seus meios de controle podem ser sufocados por traços autoritários na gestão de políticas públicas, a depender da matiz ideológica do mandatário.

\section{Referências}

1. Barzelay M, Cortzár J. Una guía práctica para la elaboración de estudios de caso sobre buenas prácticas en gerencia social [Internet]. Washington: Instituto Interamericano para el Desarrollo Social; 2004. Disponível em: https://publications.iadb.org/es/publicacion/15330/unaguia-practica-para-la-elaboracion-de-estudios-de-casosobre-buenas-practicas

2. Ribeiro JM, Moreira, MR, Ouverney, AM, Pinto LF, Silva, CMFP. Federalismo e políticas de saúde no Brasil: características institucionais e desigualdades regionais. Ciência \& Saúde Coletiva [Internet]. 2018; 23(6):1777-1789. Disponível em: 
Revista Eletrônica Gestão \& Saúde ISSN: 1982-4785 Neto JMR

https://www.scielo.br/scielo.php?pid=S1413$\underline{81232018000601777 \& \text { script }=\text { sci abstract\&tlng }}=$ pt.

3. Carvalho CM; Afonso JRR. Coordenação e relações intergovernamentais em federações avançadas: algumas lições para o Brasil. RJLB [Internet]. 2018; 6:15711604. Disponível em: http://www.cidp.pt/revistas/rjlb/2018/6/2018_06_1571 _1604.pdf.

4. Souza C. Uniformidade, autonomia e coordenação de políticas públicas. Cad. Saúde Pública [Internet]. 2019; 35 (2):1-14. Disponível em: https://www.scielo.br/scielo.php?script=sci_arttext\&pi $\mathrm{d}=$ S0102-311X2019000803002

5. Menicucci TMG, Costa, LA, Machado JA. Pacto pela saúde: aproximações e colisões na arena federativa. Ciência \& Saúde Coletiva [Internet]. 2018; 23(1):29-40. Disponível em:

https://www.scielo.br/scielo.php?pid=S1413$\underline{81232018000100029 \& \text { script=sci_abstract\&tlng=pt. }}$.

6. Schmidt F; Mello J; Cavalcante P. Coordenação governamental na crise da Covid-19: breve proposta de ação. Radar: tecnologia, produção e comércio exterior [Internet]. Brasília: Ipea, 2020. Disponível em: http://repositorio.ipea.gov.br/bitstream/11058/10116/1/ Radar_62_coordena\%C3\%A7\%C3\%A3o.pdf

7. Lotta G; Gonçalves R; Bietelman M. A Coordenação Federativa de Políticas Públicas: uma análise das políticas brasileiras nas últimas décadas. Cadernos Gestão Pública e Cidadania [Internet]. 2014; 19(64):1$17 . \quad$ Disponível em: http://bibliotecadigital.fgv.br/ojs/index.php/cgpc/article /view/5817

8. Souza C. Coordenação de políticas públicas. Brasília: Enap; $2018 . \quad$ Disponível em: https://repositorio.enap.gov.br/bitstream/1/3329/1/Livr o_Coordena\%C3\%A7\%C3\%A3o\%20de\%20pol\%C3\% ADticas $\% 20 \mathrm{p} \% \mathrm{C} 3 \%$ BAblicas.pdf

9. Gaetani F. La dinámica de la coordinación en el ámbito del Ejecutivo. Una reflexión a partir de las variaciones y contrastes en los dieciséis años de Cardoso y Lula. In: Grau, NC; Toro, JCF; Sáez, MA. (Orgs.). Fortalecimiento del alto gobierno: aproximaciones conceptuales. Caracas: Clad:425-453, 2011.

10. Souza GCA, Costa ICC. O SUS nos seus 20 anos: reflexões num contexto de mudanças. Saúde Soc [Internet]. 2010; 19(3):509-517. Disponível em: https://www.scielo.br/scielo.php?pid=S0104$\underline{12902010000300004 \& \text { script }=\text { sci abstract\&tlng }=p t}$

11. Ribeiro JM; Moreira MR. A crise do federalismo cooperativo nas políticas de saúde no Brasil. Saúde Debate [Internet]. 2016; 40 (n.spe):14-24, dez,. Disponível

em:

https://www.scielo.br/scielo.php?pid=S0103-

$11042016000500014 \&$ script=sci_abstract\&tlng=pt

12. Carnut L; Narvai PC. Avaliação de desempenho de sistemas de saúde e gerencialismo na gestão pública brasileira. Saúde Soc [Internet]. 2016; 25(2):290-305. Disponível em:
As fragilidades do federalismo cooperativo...

https://www.scielo.br/scielo.php?pid=S0104$12902016000200290 \&$ script $=$ sci abstract\&tlng $=p t$

13. Miranda GDM.; Mendes ACG; Silva ALA. O desafio da organização do Sistema Único de Saúde universal e resolutivo no pacto federativo brasileiro. Saúde Soc [Internet]. 2017; 26(2):329-335. Disponível em:

https://www.scielo.br/scielo.php?script=sci_abstract\&p $\mathrm{id}=\mathrm{S} 0104-$

$12902017000200329 \& \operatorname{lng}=\mathrm{en} \& \mathrm{nrm}=\mathrm{iso} \& \mathrm{t} \operatorname{lng}=\mathrm{pt}$

14. Araújo CEL; Gonçalves GQ; Machado JA. Os municípios brasileiros e os gastos próprios com saúde: algumas associações. Ciência \& Saúde Coletiva [Internet]. 2017; 22(3):953-963. Disponível em: https://www.scielo.br/scielo.php?pid=S1413$\underline{81232017002300953 \& \text { script }=\text { sci abstract\&tlng }}=$ pt

15. Rossi RC; Silva AS. O Consórcio do Nordeste e o federalismo brasileiro em tempos de Covid-19. Espaço e Economia [Internet]. Disponível em: http://journals.openedition.org/espacoeconomia/13776 16. Correio Braziliense. Entenda a operação de repatriação dos brasileiros que estão na China. [Internet]. 03 fev 2020. [Acesso em 08 de jul 2020]. Disponível

em: https://www.correiobraziliense.com.br/app/noticia/bras il/2020/02/03/interna-brasil,825213/entenda-aoperacao-de-repatriacao-dos-brasileiros-que-estao-nachina.shtml

17. Brasil. Ministério da Saúde. Plano de Contingência Coronavirus - COVID 19. Brasília, 2020. Disponível em:https://portalarquivos2.saude.gov.br/images/pdf/20 20/fevereiro/13/plano-contingencia-coronavirusCOVID19.pdf

18. Koga NM; Palotti PLM; Goelnner IA; Couto BG. Instrumentos de políticas públicas para o enfrentamento do vírus da Covid-19: uma análise dos normativos produzidos pelo executivo federal. Nota Técnica 31. Brasília: Ipea, 2020. Disponível em: https://www.ipea.gov.br/portal/index.php?option=com content $\&$ view $=$ article $\&$ id $=35429$

19. Correio Braziliense. Caiado evita críticas a Bolsonaro, mas defende distanciamento. [Internet]. 11 Abr 2020. [Acesso em 08 de jul 2020]. Disponível em: https://www.correiobraziliense.com.br/app/noticia/polit ica/2020/04/11/interna_politica,843846/caiado-evitacriticas-a-bolsonaro-mas-defende-distanciamento.shtml 20. Brasil. Ministério da Saúde. Portaria n. 1.587, de 19 de junho de 2020. Institui, no âmbito do Ministério da Saúde, a Força Tarefa de Fundamentação. Disponível em: https://www.in.gov.br/en/web/dou/-/portaria-n1.587-de-19-de-junho-de-2020-262754005

21. O Estado de São Paulo. Quem reabre o Brasil não sou eu, é governador e prefeito', diz Bolsonaro a apoiador. [Internet]. 14 Abr 2020. [Acesso em 08 de jul 2020]. Disponível em: https://politica.estadao.com.br/noticias/geral,quemreabre-o-brasil-nao-sou-eu-e-governador-e-prefeitodiz-bolsonaro-a-apoiador,70003271096 
Revista Eletrônica Gestão \& Saúde ISSN: 1982-4785 Neto JMR

22. Bevir M. Governança democrática: uma genealogia. Rev. Sociol. Polít.Curitiba [Internet]. 2011; 19(39):103$114 . \quad$ Disponível em: https://www.scielo.br/scielo.php?pid=S0104$44782011000200008 \&$ script $=$ sci_abstract\&tlng $=$ pt 23. O Globo. Em defesa de mais circulação, Bolsonaro volta a criticar restrições. [Internet]. 9 Abr 2020. [Acesso em 08 de jul 2020]. Disponível em: https://oglobo.globo.com/brasil/em-defesa-de-maiscirculacao-bolsonaro-volta-criticar-restricoes-

\section{5}

24. O Globo. Planalto 'barra' representante de secretários estaduais de Saúde na posse de Teich. [Internet]. 17 Abr 2020. [Acesso em 08 de jul 2020]. Disponível em: https://oglobo.globo.com/brasil/planalto-barra-

representante-de-secretarios-estaduais-de-saude-na-

posse-de-teich-diz-entidade-1-24378325

25. Frente Nacional dos Prefeitos. Nota Oficial - FNP repudia declarações do presidente Jair Bolsonaro. [Internet]. 9 Abr 2020. [Acesso em 10 de jul 2020]. Disponível em: https://www.fnp.org.br/noticias/item/2267-nota-oficialfnp-repudia-declaracoes-do-presidente-jair-bolsonaro

26. Lopez FG; Palotti PLM; Tolentino SC; Koga NM. Mapeamento dos profissionais de saúde no Brasil: alguns apontamentos em vista da crise sanitária da Covid-19. Nota Técnica 30. Brasília: Ipea, 2020. Disponível em: https://www.ipea.gov.br/portal/index.php?option=com content $\&$ view $=$ article $\&$ id $=35426 \&$ Itemid $=6$

27. Correio Braziliense. Bolsonaro ataca Rodrigo Maia: "Péssima atuação". [Internet]. 16 Abr 2020. [Acesso em 08 de jul 2020]. Disponível em: rebhttps://www.correiobraziliense.com.br/app/noticia/p olitica/2020/04/16/interna_politica,845402/bolsonaroataca-rodrigo-maia-pessima-atuacao.shtml

28. Almeida A. Relações executivo-legislativo e governabilidade à luz da crise do Covid-19. Nota Técnica 34. Brasília: Ipea, 2020. Disponível em: http://repositorio.ipea.gov.br/bitstream/11058/9855/1/N T 34_Diest_Rela\%c3\%a7\%c3\%b5es\%20Executivo_L egislativo\%20e\%20Governabilidade\%20\%c3\%a0\%20 Luz\%20da\%20Crise\%20Da\%20Covid_19.pdf

29. Correio Braziliense. Repercussão: após manifestação pró-regime militar, Bolsonaro sofre críticas. [Internet]. 19 Abr 2020. [Acesso em 08 de jul 2020]. Disponível em: https://www.correiobraziliense.com.br/app/noticia/polit ica/2020/04/19/interna_politica, 846293/repercussaoapos-manifestacao-pro-regime-militar-bolsonaro-sofrecri.shtml

30. Moraes RF. Medidas legais de incentivo ao distanciamento social: comparação das políticas de governos estaduais e prefeituras das capitais no Brasil. Nota Técnica 16. Ipea: Brasília, 2020. Disponível em: https://www.ipea.gov.br/portal/index.php?option=com content $\&$ view $=$ article $\&$ id $=35462 \&$ Itemid $=4$
As fragilidades do federalismo cooperativo... Participação dos autores na elaboração do Artigo Teórico - Empírico :

João Mendes da Rocha Neto atuou na concepção e planejamento do ensaio, elaboração da revisão teórica, realizou o levantamento dos dados estáticos e normativos, bem como das matéria jornalísticas incorporadas ao ensaio ,interpretação do conjunto de informações mencionadas, esboço do texto submetido ,ajuste na redação do ensaio, segundo orientações dos pareceristas e editores, submeteu a versão finalizada do ensaio.
Recebido: 30.06 .2020

Revisado: 04.08.2020

Aprovado: 05.08.2020 